\title{
CIÊNCIA FORENSE: INTERSEÇÃO JUSTIÇA, CIÊNCIA E TECNOLOGIA
}

Forensic Science: the Intersection of Justice, Science and Technology

Patrícia Fachone*

Léa Velho**

\section{Resumo}

Este trabalho propicia noções sobre a ciência forense evidenciando sua origem nas relações entre ciência e justiça. Enfoca-se a relação ciência, crime e sociedade bem como a procedência da credibilidade da perícia criminal, que é, conforme se argumenta, a operadora da ciência forense. $\mathrm{O}$ desenvolvimento científico verificado nos últimos 100 anos forneceu ferramentas e técnicas de uso potencial para a investigação criminal em nossos dias. Sob o prisma da teoria da evidência e da correspondência a perícia criminal utiliza-se de ciência e técnica no processamento de evidências oriundas de supostos crimes, e esse resultado faz a correspondência, com credibilidade, à narrativa dos fatos investigados. A ciência forense demanda transformações do conhecimento científico e tecnológico para atender a necessidades humanas significativamente relevantes. Para aprimorá-la, no Brasil, o modo de cooperação entre os peritos oficiais criminais e a comunidade científica é indicado.

* Perita Oficial Criminal da Secretaria de Estado de Justiça e Segurança Pública-MT; mestranda do curso de Pós - graduação em Política Científica e Tecnológica pela Unicamp. Email: patriciafachone@ seguranca.mt.gov.br

** Professora Titular do Departamento de Política Científica e Tecnológica da Universidade Estadual de Campinas; mestrado em Agronomia pela Universidade Estadual Paulista Júlio de Mesquita Filho (1979); doutorado em Política Científica e Tecnológica pelo Science Policy Research Unit - SPRU, University of Sussex, Reino Unido (1985); pós-doutorado no Department of Rural Sociology da Universidade de Ohio, USA. Email: velho@ige.unicamp.br 
Palavras-chave: Sistema de segurança pública e justiça. Política científica e tecnológica. Ciência forense. Transformações do conhecimento científico e tecnológico. Cooperação.

\section{Abstract}

This paper offers some notions about forensic science and its origin, putting in evidence the relationship between science and justice. The focus is on the relationship science, crime, and society and on the origin of the criminal expertise's credibility which is, according to arguments, the operator of Forensic Science. The scientific development verified in the last 100 years has provided potential tools and techniques to use in current criminal investigation. In sight of the evidence and the correspondence theory the forensic experts use science and technique to process evidences originated from supposed crime scenes, and this result establishes the correspondence, in a credible way, for the narrative of inspected facts. The Forensic Science requires changes in scientific and technological knowledge to attend significantly relevant human necessities. In order to attain improvement in Brazil, cooperation is recommended between the criminal experts and the scientific community.

Keywords: Public security and justice system. Science and technology policy.Forensic science. Scientific and technological knowledge changes. Cooperation

\section{INTRODUÇÃO}

Este texto tem o objetivo de delinear as relações entre justiça e ciência que conformam o que se denomina 'ciência forense'. Na concepção aqui adotada para ciência forense, ela se constitui em um sistema (todo) que engloba diversos componentes, dos quais dois se destacam, quais sejam, a justiça e a ciência (partes).

Pascal' se referia ao complexo todo-parte, dizendo: "só posso compreender um todo se conheço, especificamente, as partes, mas só posso 
compreender as partes se conhecer o todo", denotando a importância da visão do todo ao estudar uma de suas partes e vice-versa, numa dinâmica de reciprocidade. Temos, portanto, o fenômeno da interdependência, em que o foco da organização do sistema é posto nas interações entre seus componentes.

Segundo Edgar Morin (1990, p. 257-275), não podemos mais considerar um sistema complexo à luz do reducionismo, que quer compreender o todo partindo da qualidade das partes (apenas); sequer à luz do holismo, que não é menos simplificador e que descuida das partes para compreender o todo. Em sua obra, Morin, ao abordar o macroconceito do paradigma 'sistema', destaca que a problemática do sistema não se resolve na relação todo-partes, e o paradigma holista esquece dois termos capitais: interações e organização.

Sob este prisma, a idéia de 'sistêmico' que se pretende conferir é aquela em que cada parte interage com suas partes menores constituintes e com o próprio sistema que integra. Assume-se, também, que os sistemas se organizam com os demais sistemas e que há interdependência destes com o contexto mais amplo, seja o meio ambiente ou o ambiente sóciocultural e histórico.

De certo modo, está, entre os princípios da ciência clássica, a dissociação entre o sujeito e o seu objeto de estudo, originada no sistema dualístico (onde o mundo se divide em duas entidades separadas, o corpo e o espírito) formulado por Descartes. Para Morin (1990, p. 137) em vista disso, "ignorou-se que as teorias científicas não são o puro e simples reflexo das realidades objetivas, mas os co-produtos das estruturas do espírito humano e das condições socioculturais do conhecimento". Lacan (1998, p. 877) corrobora ao dizer que "(...) esse sujeito faz parte da conjuntura que produz a ciência em seu conjunto".

Nessa acepção, ao identificar as relações entre justiça e ciência, fica clara a possibilidade de haver leitores que, especializados na primeira vertente de conhecimento, tenham dificuldades de se comunicar com aqueles da outra. Por certo, a um jurista não seria necessário definir 'crime'; por outro lado, a um estudioso da filosofia ou da sociologia do conhecimento científico e tecnológico seria dispensável conceituar 'ciência'. Dessa forma, neste texto 
optou-se por apresentar o conceito de termos comumente empregados no âmbito dos sistemas de segurança pública e justiça criminal, assim como no de ciência e tecnologia.

Para alcançar o objetivo proposto, este artigo foi estruturado em três seções, além desta introdução e das considerações finais. A primeira seção apresenta noções sobre o sistema de segurança pública e justiça criminal; a seção seguinte oferece noções sobre o sistema de ciência e tecnologia (C\&T). A terceira seção então, aborda as relações entre os dois sistemas apresentados que se constituem, conforme sustenta-se aqui, na ciência forense. Para tanto, enfoca-se a relação ciência, crime e sociedade bem como a procedência da credibilidade da perícia criminal, que é, segundo se argumenta, a operadora da ciência forense. Finalmente, consideram-se evidências de que a ciência para fins forenses possui, em sua rotina, demandas de transformações do conhecimento e tecnologia, para o que se tornam necessários a pesquisa científica e o crédito conferido pelo rigor acadêmico na formação dos recursos humanos. Para aprimorá-la, no Brasil, o modo de cooperação entre os peritos criminais e a comunidade científica é indicado.

\section{NOÇÕES SOBRE O SISTEMA DE SEGURANÇA PÚBLICA E JUSTIÇA CRIMINAL}

\section{Antecedentes do sistema de segurança pública e justiça criminal}

A partir do momento em que o homem passou a conviver em sociedade, surgiu a necessidade de se estabelecer uma forma de mediar os diferentes e, principalmente, antagônicos interesses que sobrevêm da vida em comunidade (CAPEZ, 2005, p. 4). Nesse diapasão, o autor destaca que "não existe sociedade sem direito (ubi societas ibi jus), desempenhando este, a função ordenadora das relações sociais”. Então, o delito, aos olhos de Tarde ${ }^{2}$, é socialmente definido, pois: "o caráter lícito ou ilícito das ações, por exemplo, do homicida em legítima defesa ou por vingança, (...), é determinado pela opinião dominante no grupo social de que se faz parte."

Capez (2005, p. 6-7) explana como surgiu a intervenção de terceiro na solução do conflito: "inicialmente com a escolha, pelos próprios conflitantes, de um árbitro imparcial. Essa escolha recaía, em geral, sobre sacerdotes, 
que julgavam de acordo com a vontade dos deuses, ou sobre anciãos, que decidiam de acordo com os costumes e tradições locais." Nesse sentido, ao abordar a sociologia do Direito, Max Weber $(1999$, p. 6) denota que o veredicto, também era conseguido "por meio de oráculos e meios mágicos (...)".

Modernamente, o estado racional exerce o poder com o monopólio da violência legítima e, no âmbito da justiça, exige do juiz - "em parte, em nome de normas jurídicas positivas, em parte, com base em teorias do direito - que fundamente suas decisões em análises científicas, em princípios materiais, na moralidade ou na eqüidade" (WEBER, 1999, p. 4).

Os breves antecedentes acima permitem inferir o deslocamento da magia e de crenças religiosas pela ciência na fundamentação de sentenças judiciais. Apresenta-se, a seguir, o conceito de crime, e então, de forma simplificada, o sistema de segurança pública e justiça criminal no Brasil contemporâneo, enfocando o papel da perícia oficial criminal.

\section{Conceitos e classificação}

A vítima é o sujeito passivo e o autor é o sujeito ativo da infração penal. A doutrina jurídica, ora prevalente, conceitua crime como toda ação ou omissão humana típica, antijurídica e culpável.

Os crimes, que podem ser consumados ou tentados, conformam diversas categorias, entre elas, aqueles cometidos contra: o patrimônio, a pessoa, a vida, a honra, a propriedade intelectual, o sentimento religioso, a fé pública, a administração da justiça, etc. Para cumprir o objetivo de apurar as circunstâncias e identificar o(s) autor (es) do crime e, mediante as provas, processar e julgar determinando a execução de pena conforme 0 conjunto legal determina, é que o Estado brasileiro dispõe de um sistema de segurança pública e justiça criminal.

\section{Noções sobre o Sistema de Segurança Pública e Justiça Criminalno Brasil contemporâneo}

Algumas das partes que compõem esse complexo sistema estão consignadas na Constituição da República Federativa do Brasil (CF, 1988), como: o Poder Judiciário, as funções essenciais à justiça, e a segurança pública. A noção de sistema, já abordada na introdução, permite-nos aqui, de 
forma sucinta, descrever diretamente o panorama geral deste conjunto de elementos que têm, entre si, uma relação ordenada.

\section{Segurança Pública}

De acordo com a CF, 1988, a segurança pública ${ }^{3}$ é dever do Estado, direito e responsabilidade de todos; é exercida para a preservação da ordem pública e da incolumidade das pessoas e do patrimônio, através dos seguintes órgãos: I - polícia federal; II - polícia rodoviária federal; III - polícia ferroviária federal; IV - polícias civis; V - polícias militares e corpos de bombeiros militares.

Como ilustração do funcionamento do sistema de segurança pública, utiliza-se um exemplo de cena de crime, pois neste contexto ocorre uma clara interação entre os vários componentes deste sistema.

No acontecimento de uma situação (hipotética) de crime que deixa vestígios, por exemplo, um homicídio com localização de cadáver, a polícia militar, que tem por competência o policiamento ostensivo e a preservação da ordem pública, é chamada pela população ou, ao realizar o policiamento preventivo, identifica a ocorrência do evento. Desta forma, a polícia militar é, normalmente, a primeira componente do sistema do segurança pública a chegar à cena do crime. Dependendo do tipo do crime (por exemplo, afogamento suspeito de intencional) o corpo de bombeiros militar também cumprirá algumas de suas funções nesse momento.

Então, a polícia civil ${ }^{4}$, é acionada, para que, a partir do conhecimento da ocorrência do crime (notícia-crime), investigue e elucide quais as circunstâncias em que se passaram o fato e identifique o autor da ação delituosa. Todas as conclusões devem estar provadas.

A perícia oficial criminal é requerida a estar na cena do crime buscando os vestígios que possam elucidar os fatos e o autor, os quais são coletados e posteriormente analisados, fundamentados pelos conhecimentos de ciência e tecnologia disponíveis. O resultado da análise desses vestígios materializa a prova, transposta aos autos em formato de laudo. Dessa forma, a prova material é, em grande parte, função precípua do colegiado de bacharéis em diversas áreas do conhecimento, aqui denominado genericamente de perícia criminal. 
Esse primeiro momento da persecução penal é encerrado com 0 relatório, última peça do inquérito policial, presidido pelo delegado de polícia.

Funções essenciais à Justiça

É o ministério público o responsável por analisar o inquérito e solicitar novas diligências, caso julgue necessário; solicitar o arquivamento dos feitos ou oferecer a denúncia, (sendo que a partir desse ponto é que se pode, tecnicamente, falar em acusado) que, sendo aceita pelo Poder Judiciário, inaugura o processo penal. Entre outras incumbências está a de: "promover, privativamente, a ação penal pública, na forma da lei; exercer o controle externo da atividade policial, na forma da lei complementar (...); requisitar diligências investigatórias e a instauração de inquérito policial, indicados os fundamentos jurídicos de suas manifestações processuais" (CF, 1988: Título IV, Capítulo IV, Seção I). O ônus da prova incumbe a quem alega o fato criminoso, por conseguinte, o parquet ${ }^{5}$ é autoridade legítima a requisitar perícias complementares ou novas, ao órgão responsável por executá-las. Já ao acusado cabe provar as causas excludentes da antijuridicidade, da culpabilidade.

Também o advogado é indispensável à administração da justiça. Além disso, provém da orientação jurídica e defesa, em todos os graus, dos necessitados, a essencialidade da defensoria pública.

\section{Poder Judiciário}

Ao receber a denúncia oferecida pelo ministério público inicia-se a ação penal. Vale ressaltar que o processo penal (tramita no âmbito do poder judiciário), em seu percurso se norteia por princípios diversos aos do inquérito policial, mormente o do contraditório, da igualdade e da ampla defesa, que se conectam intimamente, e o da verdade real.

O princípio da verdade real, sob a ótica de Bonfim (2005, p.4849), define-se como:

"Toda a atividade processual, em especial a produção da prova, deve conduzir ao descobrimento dos fatos conforme se passaram na realidade. O conjunto instrutório deve refletir, 
no maior grau de fidelidade possível, os acontecimentos pertinentes ao fato investigado. (...) Isso porque o princípio da verdade real contrapõe-se ao princípio da verdade formal, (...).".

A possibilidade concreta de aplicação de penas restritivas de liberdade, e também, a qualidade das condutas tuteladas pelo direito penal material, fazem com que se intensifique o clamor social sobre questões atinentes a esse âmbito de atuação do judiciário. Dessa forma, Capez (2005, p.26-27) argumenta que: “(...) o juiz tem o dever de investigar como os fatos se passaram na realidade, não se conformando com a verdade formal constante dos autos." Assim, o Código de Processo Penal (CPP) em seu art. 156 dispõe sobre princípio que é próprio ao processo penal: “o juiz poderá, no curso da instrução, ou antes de proferir sentença, determinar, de ofício, diligências para dirimir dúvidas sobre ponto relevante". Para alcançar esse fim, inúmeras vezes, e praticamente em todas as fases do processo penal, a perícia oficial criminal é consultada ou novamente requisitada no afã de desvendar a "verdade real".

Havendo sentença condenatória, o sistema prisional, normalmente um órgão do poder executivo, é responsável pela efetiva execução da pena.

\section{NOÇÕES SOBRE O SISTEMA DE CIÊNCIA E TECNOLOGIA}

\section{Antecedentes sobre o sistema de ciência e tecnologia}

Nos séculos XVII, XVIII e XIX países como Inglaterra, França e Estados Unidos criaram instituições como a "Royal Society", "L'École Pratique des Hautes Études" e "National Academy of Sciences", respectivamente, com fulcro de estimular a pesquisa científica. No século $\mathrm{XX}$, conselhos de pesquisa foram concebidos com a função de associar o trabalho científico às decisões políticas do governo.

Com o desenvolvimento da bomba atômica, a ciência obteve 0 reconhecimento de assunto de Estado ${ }^{6}$. Esse histórico episódio da humanidade pode ser retratado, em parte, pela frase de Robert K. 
Merton (1968, p.655) "O homem de ciência pode ser transformado em homem de guerra e atuar em conseqüência".

Com efeito, o início da institucionalização do sistema de ciência e tecnologia está incrustado no contexto da Segunda Guerra Mundial. Em 17 de novembro de 1944, Franklin D. Roosevelt, presidente dos Estados Unidos, escreveu à Vannevar Bush, responsável pelo escritório de pesquisa e desenvolvimento científico daquele País: "Novas Fronteiras para a mente estão diante de nós. Se forem exploradas com a mesma visão, arrojo e ímpeto com os quais empreendemos esta guerra, poderemos criar melhores empregos, mais frutíferos; e uma vida melhor (...)".

Em resposta à demanda presidencial é que, após consultar seus pares, Vannevar Bush remeteu o relatório intitulado "Science The Endless Frontier ${ }^{7 "}$, que consiste em um marco de referência para a política científica e tecnológica no Pós-Guerra.

Conforme Pábon Escobar, S. e Velho, L. (2002, p.2), o modelo de política científica e tecnológica gerado após a Segunda Guerra Mundial foi reproduzido na América Latina, com a ajuda de organismos internacionais como a Unesco (Organização Educacional, Científica e Cultural das Nações Unidas) e, posteriormente a OEA (Organização dos Estados Americanos).

$\mathrm{O}$ relatório acima mencionado projeta a primeira versão da política científica e tecnológica, a partir da qual é construído o seu aparato oficial, que em traços gerais, delineiam, inclusive na atualidade, a forma de funcionamento dos sistemas de ciência e tecnologia.

\section{Policiamento do conhecimento científico}

Conhecimento é um substantivo empregado comumente. Ele pode se referir a um endereço, a uma pessoa, aos elementos da prática da vida e da experiência em geral. O ponto de partida para o conhecimento científico é a observação de experiências cotidianas, posteriormente submetidas a experimentos, cujos resultados confirmam ou refutam hipóteses. Dessa forma, o conhecimento científico é aquele que suplanta o do senso comum, pois atribui uma função a um aspecto observado e testado experimentalmente. 
O status atribuído ao adjetivo científico tem disseminado o seu uso, inclusive indevidamente. Já no século XVII, nas primeiras academias e sociedades científicas, os cientistas começaram, conforme Davyt e Velho (2000), "a criar maneiras próprias de se relacionar e de controlar o trabalho científico. Uma delas diz respeito ao controle do registro dos 'resultados' que deveriam receber o rótulo de científico." Os autores esclarecem que: "para obter credibilidade (...), a crença individual ou a experiência tinha que ser efetivamente comunicada aos outros, isto é, fazer sua passagem do domínio privado para o público." Para tanto, as pesquisas a serem publicadas deveriam estar minuciosamente descritas, a ponto de outros pesquisadores poderem replicá-las e alcançarem os mesmos resultados, sendo então julgadas (aprovadas ou não) pelos seus pares ${ }^{8}$. Assim, as comunidades de pesquisa, visando preservar sua credibilidade, adotaram regras estritas de avaliação da atividade de seus integrantes. É essa prática de avaliação que valida o conhecimento científico.

A avaliação pelos pares, principalmente nos conselhos de pesquisa e nas universidades, seja para publicação, ou através de congressos, palestras etc, é tomada aqui como evidência de que o que delimita o conhecimento científico e o não-científico é o consenso da comunidade científica.

\section{Conceitos e classificação}

Ciência é conceituada por Kline e Rosenberg (1986, p.287) como “a criação, descoberta, verificação, colação, reorganização e disseminação de conhecimento sobre as naturezas física, biológica e social”. Merton (1968, p.653) postula que "a meta institucional da ciência é a ampliação dos conhecimentos comprovados”. O progresso da ciência é possível graças ao trabalho da comunidade científica, que abarca o conjunto de atividades científicas e tecnológicas que produzem novo conhecimento ou se apóiam sobre os conhecimentos existentes para desenvolver novas técnicas (Manual Frascati, 2002).

A ciência, suas atividades e seus produtos são classificados, pela CAPES $^{9}$, de acordo com o campo disciplinar ou do conhecimento, 
resumidamente: Ciências Exatas; Ciências Biológicas; Engenharias; Ciência da Saúde; Ciências Sociais Aplicadas; Lingüística, Letras e Artes; Outros (Multidisciplinar).

A idéia de tecnologia como ciência aplicada está contida no senso comum. Na verdade, o termo tecnologia tem uma ampla abrangência e engloba ferramentas, equipamentos, técnicas, métodos, produtos, processos, que possibilitam o aumento da capacidade humana.

Para cumprir o objetivo de formar recursos humanos altamente qualificados, ampliar o conhecimento científico e tecnológico e de iniciar novos cientistas, por intermédio de atividades de ensino, pesquisa e extensão, é que as iniciativas pública e privada dispõem do sistema de C\&T.

\section{Noções sobre o sistema de ciência e tecnologia no Brasil contemporâneo}

Furtado (2005, p. 41-45) afirma que o sistema de C\&T brasileiro ainda está muito concentrado no Estado e que existe, de certa forma, uma continuidade em sua forma de atuação na ciência e tecnologia desde 0 pós-guerra.

Explorando os preceitos constitucionais vigentes, vislumbra-se o que a assembléia constituinte observou para o sistema de ciência e tecnologia ${ }^{10}$ brasileiro. O caput do artigo 218 e seus parágrafos primeiro e segundo prescrevem que:

"oEstadopromoveráe incentivaráodesenvolvimentocientífico, a pesquisa e a capacitação tecnológica. $\$ 10^{\circ}$ A pesquisa científica básica receberá tratamento prioritário do Estado, tendo em vista o bem público e o progresso das ciências. $\$ 2 .^{\circ}$ A pesquisa tecnológica voltar-se-á preponderantemente para a solução dos problemas brasileiros e para o desenvolvimento do sistema produtivo nacional e regional. (...)”.

Um dos principais mecanismos que o Estado utiliza para atender o dispositivo constitucional é o de fomentar a pesquisa através de financiamento. Furtado destaca que a partir de 1993/1994, houve a iniciativa de aumentar o gasto público em C\&T, por intermédio de agências como a Capes, $\mathrm{CNPq}$, 
Finep, e alguns governos estaduais seguiram essa tendência. Em 1998, foram criados os fundos setoriais vinculando recursos a diversos setores econômicos e áreas de pesquisa.

De forma geral, os professores titulados doutores, especialmente das universidades públicas brasileiras, além de ministrarem aulas na graduação, se ocupam, em parte, de pesquisa e desenvolvimento, sendo os responsáveis pela iniciação de novos cientistas.

Ao versar sobre a função do dogma na investigação científica, Kuhn (1979, p.53-80) deixa claro que os cientistas não são a única categoria de profissionais que adquire, pela educação, um conjunto de padrões, instrumentos e técnicas, que usarão em seu próprio trabalho. Entretanto, descreve que: “(...) uma vista rápida que seja da pedagogia científica sugere que ela pode induzir uma rigidez profissional praticamente impossível de alcançar noutros campos, exceto talvez na teologia." E complementa que a característica mais extraordinária da educação científica, seja a de escrever manuais especialmente para estudantes.

A Universidade é a instituição fonte de novos cientistas que, no Brasil, são os principais protagonistas e interlocutores da ciência e da tecnologia. Portanto, a Universidade é a instância legítima e acreditada para criar, validar e transferir o conhecimento científico e tecnológico nas diversas áreas, entre elas, a ciência forense.

\section{CIÊNCIA FORENSE}

\section{Ciência, crime e sociedade}

O século XX foi palco de desenvolvimentos científicos e tecnológicos que acarretaram transformações no dia-a-dia da sociedade a uma velocidade nunca vista antes. Moreira (2002, p. 11) refere-se à tecnologia como "parte integrante da vida do ser humano e como tal a influencia e modifica seu modo de viver ao mesmo tempo em que é modificada por ele." Naturalmente, as relações sociais também sofreram transformações em função da ciência e da tecnologia terem sido incorporadas ao cotidiano da vida moderna. Por um lado, os novos conhecimento em C\&T permitiram o aumento dos tipos e formas (e, por consequiência, quantidade) de crimes. Nos idos de 1950, 
quantas pessoas imaginariam que observaríamos, no momento atual, a utilização das Tecnologias de Informação e Comunicação como meio para prática de crimes como o de pedofilia? Por outro lado, o desenvolvimento exponencial que se verificou na ciência dos últimos 100 anos forneceu ferramentas e técnicas de uso potencial para a investigação criminal em nossos dias. Na mesma década de 50, seria factível supor que, a partir de um chiclete mastigado poderiam ser coletadas células descamadas da mucosa da boca, anteriormente contidas na saliva que, submetida a análises comparativas de DNA pode levar à identificação do autor de um crime?

Bruno Latour (2000, p.14) esclarece que a expressão caixa-preta é usada em cibernética sempre que uma máquina ou um conjunto de comandos se revela complexo demais. Em seu lugar, é desenhada uma caixinha preta, a respeito da qual não é preciso saber nada, senão o que nela entra e o que dela sai. Em analogia, a expressão caixa-preta pode ser utilizada para se referir à ciência, em razão da alta complexidade que vem acumulando. Por seu turno, estariam aptos, os operadores do direito a formular acusações e julgamentos sem que alguém abra esta caixa-preta? Isto significa dizer que, no tocante ao espaço tecnológico ${ }^{11}$ de algum fato investigado, alguém, dotado de credibilidade e que entenda o processo pelo qual se desenvolve a informática, a genética, e outros campos científicos, deve indicar aos operadores do direito, o que e como algo ocorreu e, quando possível, por quem foi executado.

\section{Credibilidade da perícia criminal}

No âmbito do sistema de segurança pública e justiça criminal os integrantes da perícia oficial são os mais freqüentes porta-vozes da ciência. Ao representarem-na, herdam o seu prestígio e a sua credibilidade. Então, por essa razão, o laudo pericial muitas vezes poderá ser a peça principal e fundamental para condenar ou inocentar um réu, uma base decisória que direciona a investigação policial, o processo criminal e o julgamento.

Um dos princípios em que se fundamenta o poder judiciário na condução do processo penal é o da verdade real. Roland Omnès (1996, p. 264-270) discute que a questão do realismo parte de uma interrogação: “que nos ensina, então, a ciência, sobre a realidade das coisas?”. Omnès 
expõe qual a resposta dada pelo senso comum: "é que a ciência permite conhecer a realidade e saber o que esta última é verdadeiramente”.

Doravante, um hiato para trazer a explicação formulada para a verdade por Marilena Chauí (2001, p. 90): “um valor, é o verdadeiro que confere às coisas, aos seres humanos, ao mundo um sentido que não teriam se fossem considerados indiferentes à verdade e à falsidade”. Já, a não consciência sobre o estado de ignorância (o de não saber) acarreta que nada mais há para saber. Por outro lado, a incerteza é a percepção da ignorância, a confiança e as opiniões não abarcam a realidade e surgem as dúvidas e então, a insegurança. Assim, se busca a verdade para superar a incerteza. A autora nos revela que: "o desejo da verdade aparece como o desejo de confiar nas coisas e nas pessoas, isto é, de acreditar que as coisas são exatamente tais como as percebemos e o que as pessoas nos dizem é digno de confiança e crédito" (2001, p. 91).

Três concepções da verdade são apresentadas pela filósofa (Chauí, 2001, p. 99), provenientes da língua grega, da latina e da hebraica: verdade, em grego (aletheia) se refere ao que as coisas são, o verdadeiro é o evidente ou plenamente visível para a razão; em latim (veritas) se refere ao que os fatos foram, o verdadeiro é a narrativa dos fatos acontecidos; e em hebraico (emunah) se refere ao que as ações e coisas serão e significa confiança de que aquilo que foi pactuado aconteça. A autora considera que a evidência é a marca do conhecimento verdadeiro e que uma idéia é verdadeira quando corresponde à coisa que é seu conteúdo e que existe fora de nosso espírito ou de nosso pensamento.

Com base no exposto argumenta-se aqui que a teoria da evidência e da correspondência traça um conjunto de relações entre o mundo e a consciência: a ciência (seus ramos), portanto, é uma representação da realidade, abstrata, mas digna de confiança. Sob esse prisma, a perícia criminal utiliza-se de ciência e tecnologia no processamento de evidências oriundas de supostos crimes, e esse resultado (expresso em um laudo) faz a correspondência, faz a narrativa dos fatos investigados.

Lacan (1998, p. 890) indica que "a incidência da verdade como causa da ciência deve ser reconhecida sob o aspecto da causa formal". Em torno da busca da verdade, no momento da elucidação dos crimes, 
encontram-se, filosoficamente, a justiça e a ciência: a verdade como a causa para ciência e a finalidade para justiça.

\section{Conceitos e classificação}

Ciência forense é a classificação dada aos esforços de geração e transferência de tecnologia e ciência com a finalidade de elucidar questões relativas ao âmbito do sistema de segurança pública e justiça criminal. Já, perícia criminal é a busca da verdade real das circunstâncias do crime a partir de evidências materiais geradas pelo fato criminoso, em função de conhecimento tecnológico e científico comprovado, com a finalidade de fundamentar os procedimentos legais até o julgamento.

Constituem objetos de estudo perseguidos pelos peritos criminais, ilustrativamente: fios de cabelos; manchas de sangue, esperma, saliva; tecidos biológicos; fragmentos de impressões digitais, de objetos (vidro, plástico, etc.); vestes; cartuchos; projéteis; entre outros.

Atualmente, as séries televisivas que abordam a ciência forense têm tornado o campo mais conhecida para a população, assim como os vários ramos da ciência que contribuem para ela. Compete à perícia oficial Criminal, enquanto operadores da ciência forense, a realização de exames em algumas áreas, sem a intenção de esgotá-las; exemplifica-se abaixo:

i) Balística: verificação e análise de eficiência de armas e de munições, confronto de projetil balístico, reprodução simulada de crimes envolvendo disparo de arma de fogo.

ii) Grafoscopia e documentoscopia: confronto de grafismos; identificação de falsificação em documentos, em papel moeda, em selos, em rótulos, em cédulas, respectivamente.

iii) Fonética forense: confronto e identificação de vozes.

iv) Papiloscopia forense: confronto de impressões digitais latentes, fragmentadas ou não, relacionadas a cenas e objetos de supostos crimes. 
v) Identificação de veículos: verificação e análise de adulteração, remarcação e implante de chassi, de motor e outros componentes dos veículos.

vi) Química forense: identificação e/ou quantificação de substâncias em amostras químicas, como combustíveis, resíduos metálicos.

vii) Toxicologia forense: identificação e/ou quantificação de substâncias em amostras biológicas, como: venenos, entorpecentes e drogas em geral.

viii) Genética de identificação humana: exame comparativo de material genético (DNA).

ix) Entomologia forense: elucidação de aspectos relacionados à morte por meio do estudo de insetos e artrópodes que atuam na decomposição cadavérica.

x) Computação Forense: verificação e análise de conteúdo e/ou pirataria, etc. em hardware e software.

xi) Meio ambiente forense: verificação e análise em desmatamentos, em produtos da pesca e/ou caça ilegais, diferenciação de incêndio ambiental criminal ou acidental.

xii) Engenharia legal: verificação e análise de causas de desabamento, diferenciação de incêndio criminal ou acidental, verificação e análise em furto de energia elétrica, de água, de sinal de TV por assinatura.

xiii) Contabilidade forense: verificação e análise em documentos visando identificar falsificação de demonstrações financeiras, fraudes em seguros.

xiv) Cenas relacionadas a crime contra a vida: levantamento de evidências e análise em local de morte violenta - homicídio, suicídio, aborto, infanticídio.

xv) Cenas relacionadas a crimes contra o patrimônio: levantamento de 
evidências e análise em local de furto, arrombamento, constatação de danos.

xvi) Cenas relacionadas a acidente de tráfego: levantamento de evidências e análise em local de atropelamento, de colisão, de capotamento, realização de reprodução simulada.

xvii) Medicina legal: verificação e análise em lesões corporais, determinando sua natureza, extensão e determinação a relação causal de eventual incapacidade física; verificação e análise em cadáveres, determinando a causa mortis e, em alguns casos, o tempo de morte decorrido.

xviii) Psiquiatria forense: exames de sanidade mental.

xix) Odontologia legal: exames para verificação de traumas, para análise da idade, para identificação humana por análise de arcos dentários ou mordedura.

xx) Antropologia forense: convergem Peritos Oficiais Médicos e Odontólogos legistas na realização de exumações e realização de levantamentos antropométricos (estatura, envergadura, dentes e crânio) e se prestam a identificar um cadáver ou um indivíduo vivo.

Os profissionais que trabalham nas atividades acima relacionadas conformam a perícia criminal. Argumenta-se aqui, pelos motivos acima apresentados, relativos à importância do laudo pericial baseado em ciência e aos reflexos na sociedade ocasionados pela dinâmica do progresso científico e tecnológico, que os serviços prestados pela perícia criminal, tida como auxiliar da justiça no Brasil, adentram em um plano de imprescindibilidade para o sistema de segurança pública e justiça criminal brasileiro no período contemporâneo.

\section{Um olhar para formação profissional e pesquisa em ciências forenses}

Pesquisando na world wide web, foi possível identificar vários cursos, graduação e pós-graduação stricto sensu em ciências forenses nas 
universidades de vários países, sendo alguns exemplos discriminados a seguir:

- Canadá, em Alberta, o Mount Royal College ${ }^{12}$ oferece o curso a distância 'estudos forenses - FORE' e na faculdade de medicina da University of Calgary ${ }^{13}$, o departamento de psiquiatria apresenta uma divisão em psiquiatria forense, em Ontario, a University of Windsor ${ }^{14}$ dispõe de bacharelado em ciências forenses;

- Índia, em Utter Pradesh, a Univerdade Allahabad Agricultural Institute $^{15}$ oferece mestrado em ciências forenses, sob cronograma de 4 semestres;

- Suíça, em Lausanne ${ }^{16}$, a l'École des Sciences Criminelles, além do bacharelado em ciências forenses, proporciona pós-graduação stricto sensu como os mestrados em ciências forenses na vertente identificação e outro na vertente criminalística química, também há doutorado em ciências forenses;

- Na Inglaterra (UK), em Bournemouth, a Bournemouth University ${ }^{17}$ oferece bacharelado em ciências forenses e cena de crime e, em Londres, o Kings College ${ }^{18}$ apresenta mestrado em ciências forenses.

- Nos Estados Unidos da América (USA), no estado da Flórida, a Florida International University ${ }^{19}$ apresenta em seu programa mestrado em ciências forenses e doutorado em química com ênfase em ciências forenses.

- Na Argentina, em Buenos Aires o Instituto Universitário da Polícia Federal Argentina conduz licenciatura em criminalística ${ }^{20}$, com duração de 4 anos, aprovada pela resolução 120/91 do Ministério da Educação da Nação.

São tantas as opções de cursos de extensão, graduação e pósgraduação stricto sensu no exterior que não é viável prosseguir. O objetivo de citar os programas é apenas apontar o grau de institucionalização das ciências forenses em diferentes países. No Brasil, parte do quadro pôde ser resumida em relato, à Fundação de Amparo à Pesquisa do Estado de São Paulo, de Valter Stefani (2006), professor da Universidade Federal do Rio Grande do Sul: "Por ser uma área em que publicações em revistas de impacto são muito raras os órgãos de financiamento acabam não olhando 
para os projetos como deveriam" 21 , e por isso ele menciona manter sua rotina com pesquisas na área da química de síntese. Quanto à importância do doutorado na área das ciências forenses, o professor afirma que, "teoricamente, são profissionais que trabalham com todo um instrumental e têm um conhecimento que permitirá introduzir métodos novos de forma mais confiável". Refere-se que, em Porto Alegre, o concurso para o cargo de perito criminal para atuar em química forense na secretaria de segurança pública, é específico e atualmente conta com 2 ou 3 doutores em química.

O professor exemplifica que avanços que tornassem possível coletar impressões digitais a partir de superfícies incomuns poderiam potencializar a elucidação de casos como os de estrangulamento com a coleta de impressões digitais do assassino na pele da vítima, exaltando a necessidade de pesquisas específicas. Finaliza a reportagem comparando a polícia brasileira à norte-americana, ressaltando que hoje, nos laboratórios forenses brasileiros não se faz o que se vê nos filmes e seriados, entretanto, sustenta que "dá pra fazer com o auxílio das universidades".

\section{CONSIDERAÇÕES FINAIS}

Neste texto foram apresentadas algumas evidências das relações entre C\&T e segmentos repressivos (polícia, justiça) que demandam transformações do conhecimento tecnológico e científico para atender necessidades humanas significativamente relevantes.

As evidências sugerem que as ciências forenses estão ainda em processo de institucionalização no Brasil. Os objetivos de formar recursos humanos altamente qualificados, ampliar o conhecimento científico e tecnológico e de iniciar novos cientistas em ciência forense parecem, de forma geral, ser periféricos para as organizações brasileiras que fomentam pesquisas. Por outro lado, questões a serem respondidas em ciência forense são abundantes, sendo necessário, para aprimorá-la no Brasil, o desenvolvimento tecnológico e científico focado e o crédito conferido pelo rigor acadêmico na formação dos recursos humanos.

Assim como as disciplinas são compartimentadas, por um recurso da didática, as pastas (ministérios, secretarias) também o são. Ocorre 
que os problemas são interdisciplinares e multisetoriais e necessitam da aproximação de atores que habitualmente atuam em separado para complementarmente construírem e atuarem em soluções. "São muitas as possibilidades que o emprego de um enfoque alternativo e criativo - baseado na multidisciplinaridade e orientado por problemas, ao invés de por disciplinas - abre para o estabelecimento de linhas de pesquisa" (DAGNINO, 2004, p. 138).

Nesse sentido, e como sugerido pelo professor Valter Stefani, o modo de parceria, entre as equipes de serviços periciais e a comunidade científica e tecnológica brasileiras, indica uma forma de ampliar as possibilidades de se tornar mais competente para utilizar mais conhecimento e tecnologia que possam satisfazer necessidades prioritárias locais, do que se estivessem isoladas.

A importância da aplicação da ciência no desvendar de crimes não se dá apenas em razão da materialização da prova, da comprovação da autoria, ou da identificação do modus operandi. A relevância do setor para a sociedade é factível na consignação da inocência. Não há mensuração de quantos inocentes passaram ou passam anos presos, por exemplo, à espera de um exame de DNA que descarte a sua participação no crime. Priorizar a ciência forense é uma ação que centraliza benefícios à sociedade dispondo da ciência e tecnologia não apenas ao sistema de segurança pública e justiça criminal, mas, em última análise, a serviço dos direitos humanos.

\section{NOTAS}

1 Pascal, citado por Edgar Morin, Ciência com consciência, Rio de Janeiro: Bertrand Brasil, 1982, p.30.

2 TARDE, Criminalité comparée. Citado por Garofalo, 1997, p. 42.

3 BRASIL.CF/88. Da Defesa Do Estado E Das Instituições Democráticas, Título V, capítulo III, artigo 144 , trata da Segurança Pública.

4 Conforme $\mathrm{CF} / 88$, op. cit., art. 144 em seu $\S 4^{\circ}$ : "incumbem às polícias civis as funções de polícia judiciária e a apuração de infrações penais, exceto as militares;”.

5 Significa Ministério Público.

6 O Projeto Manhattan foi o espaço de constituição da bomba atômica. “ ...uma segunda bomba atômica, a "Fat Man" foi lançada pelo B-29 "Bock's Car" sobre Nagasaki a 9 de Agosto de 1945. Em 14 de Agosto o Japão rende-se incondicionalmente."

7 Mais informações disponíveis em: < http://www.nsf.gov/od/lpa/nsf50/vbush1945.htm >. Acesso em: 21.01.07. às $13 \mathrm{~h} 59 \mathrm{~min}$. 
8 Cf. DAVYT, Amilcar; VELHO, Léa. Op. cit. a palavra 'pares' se refere aos colegas cientistas, cuja formação permita compreender e opinar sobre o trabalho apresentado. Ocorre a revisão por pares, também, na alocação de recursos a projetos de pesquisa nas agências de fomento. Isto ocorreu, por iniciativa dos governos, frente a percepção do Estado que estaria a minimizar riscos ao financiar um projeto quando este é aprovado por outro especialista da mesma área.

9 Tabela completa de áreas do conhecimento organizada pela CAPES (Fundação Coordenação de Aperfeiçoamento de Pessoal de Nível Superior), disponível em: < http://www.capes.gov.br/export/ sites/capes/download/avaliacao/Tabela_Areasconhecimento.pdf $>$. Acesso em: 30.01.07 às $14 \mathrm{~h} 09 \mathrm{~min}$.

10 CF/88, op. cit.,Título VIII, Da Ordem Social, Capítulo IV.

11 Espaço tecnológico conforme a acepção de Herrera. v. HERRERA, A. O. The generation of technologies in rural áreas. In: World Development, Vol.9, 1981. p. 21-35.

12 Mais informações disponíveis em:< Mount Royal College, Calgary - Forensic Studies > . Acesso em: 17.01 .07 às $14 \mathrm{~h} 22 \mathrm{~min}$.

13 Mais informações disponíveis em:<University of Calgary - Forensic Psychiatry>. Acesso em: 17.01.07 às $15 \mathrm{~h} 01 \mathrm{~min}$.

14 Mais informações disponíveis em:<University of Windsor Forensic Science (BFS Hons) Program>. Acesso em: 18.01 .07 às $12 \mathrm{~h} 22 \mathrm{~min}$.

15 Mais informações disponíveis em:<Allahabad Agricultural Institute, Allahabad, India - M.Sc in Forensic Science >. Acesso em: 17.01.07 às 16h08min.

16 Mais informações disponíveis em:<Institute of Police Science and Criminology (IPSC), University of Lausanne $>$. Acesso em: 17.01.07 às $12 \mathrm{~h} 55 \mathrm{~min}$.

17 Mais informações disponíveis em:<Bournemouth University - BSc (Hons) in Forensic and Crime Scene Science $>$. Acesso em: 22.01.07 às 20h55min.

18 Mais informações disponíveis em:<Kings College, London, UK - MSc in Forensic Science> Acesso em: 22.01.07 às $21 \mathrm{~h} 30 \mathrm{~min}$.

19 Mais informações disponíveis em:<International Forensics Institute, Florida International University >. Acesso em: 22.01.07 às $22 \mathrm{~h} 12 \mathrm{~min}$.

20 Mais informações disponíveis em:<http://criminalistica.universidad-policial.edu.ar/carreras/lic crimi.htm>. Acesso em: 30.01 .07 às $14 \mathrm{~h} 50 \mathrm{~min}$.

21 Cf. DAVYT e VELHO (2000) os indicadores quantitativos da ciência provém de publicações científicas (cientometria), e destacam que: “(...), é lugar-comum assimilar a excelência científica ao reconhecimento e prestígio acadêmico internacionais, ao impacto na comunidade científica mundial, (...)".

\section{REFERÊNCIAS}

BONFIM, E. M. Curso de processo penal. São Paulo: Saraiva, 2006.

CAPEZ, Fernando. Curso de processo penal. 12ª ed., São Paulo: Saraiva, 2005.

CHAUÍ, Marilena. Convite à Filosofia. 12a ed., São Paulo: Ática, 2001.

BRASIL. Constituição da República Federativa do Brasil (1988). São Paulo, Revista dos Tribunais, 1996. 
DAGNINO, R. A Relação Pesquisa-Produção: em Busca de um Enfoque Alternativo. In: SANTOS, L. W., org., Ciência, Tecnologia e Sociedade: o desafio da interação. Londrina, IAPAR, 2004, pp.101-150.

DAVYT, Amílcar e VELHO, Léa. "A avaliação da ciência e a revisão por pares: passado e presente. Como será o futuro?" Hist. cienc. saude-Manguinhos., Rio de Janeiro, v. 7 , n. $1,2000$.

DESCARTES, René. Discours de la Méthode de Bien Conduire as Raison et Chercher la Vérité dans les Sciences. s.l., s.d., (trad. port. de Pietro Nasseti, Discurso do Método, São Paulo, Editora Martin Claret, 2000). 70p.

FURTADO, André. "Novos arranjos produtivos, estado e gestão da pesquisa pública”. Ciência e Cultura, Rio de Janeiro, v. 57, n. 1, 2005, pp. 41-45.

GAROFALO, R. [19--?] (trad. port. de Danielle Maria Gonzaga, Criminologia. Série Mestrado Jurídico, Campinas, Péritas, 1997).

KUHN, Thomas S. A função do dogma na investigação científica. In: Deus, J. D. de, A Crítica da Ciência. Rio de Janeiro: Zahar, 1979.

LACAN, Jacques. Écrits. Paris, France: Editions du Seuil, 1995. (trad. port. Vera Ribeiro. A ciência e a verdade. In: Escritos. Rio de Janeiro, RJ, Jorge Zahar, 1998.

LATOUR, Bruno. Science in Action. How to follow scientists and engineers through society. s.l., 1998. (trad. Port. de Ivone C. Benedetti, Ciência em Ação: como seguir cientistas e engenheiro sociedade afora. Biblioteca Básica. São Paulo, UNESP, 2000). ISBN 85-7139-265-X.

MERTON, Robert. K. A Ciência e a Estrutura Social Democrática. In: Sociologia. Teoria e Estrutura, São Paulo, Mestre, 1968. pp. 651-662.

MOREIRA, Lays. Informática e Educação: A (re)estruturação da prática educativa no contato com os computadores. Universidade Estadual de Campinas, Faculdade de Educação, 2002.

MORIN, Edgar. Science avec conscience. Editions du Seuil, 1990, (trad. port. de Maria D. Alexandre e Maria Alice Sampaio Dória, Ciência com consciência - $9^{\mathrm{a}}$ ed. - RJ, Bertrand Brasil, 2005).

OCDE. "Manual Frascati”. Paris, 2002. 
OMNÈS, Roland. Filosofia da ciência contemporânea. São Paulo, UNESP. ISBN 85-7139-120-3. 1996. p. 264-270.

PABÓN ESCOBAR, S. C. Institucionalização da política científica e tecnológica na Bolívia: avanços e retrocessos. Dissertação (Mestrado em Política Científica e Tecnológica). Universidade Estadual de Campinas. Campinas, SP, 2002.

STEFANI, Valter. "Ciência que desvenda crimes". Boletim Agência FAPESP, Jun 2006. Disponível em: < http://www.agencia.fapesp.br/boletim_dentro. php?id=5588> . Acessado em: 18.08.2006.

WEBER, Max. Wirtschaft und Gesellschaft: Grundriss der verstehenden Soziologie. s.l., s.d., (trad. port. de Regis Barbosa e Karen Elsabe Barbosa, Economia e Sociedade - Fundamentos da sociologia compreensiva, Vol.2, Brasília, DF, Universidade de Brasília, 1999). 